\title{
Prevalence of Depression, Anxiety and Stress among Patients Discharged from Critical Care Units
}

\author{
Mohammad Saeidi ${ }^{1}$, Alireza Safaei ${ }^{2}$, Zohreh Sadat ${ }^{3}$, Parisa Abbasi ${ }^{4}$, Masoumeh Sadat \\ Mousavi Sarcheshmeh5 ${ }^{5}$, Fariba Dehghani ${ }^{6}$, Mehran Tahrekhani ${ }^{7}$, Mohammad Abdi ${ }^{*}$ \\ ${ }^{1}$ Department of Anesthesiology and Critical Care, Qom University of Medical Sciences, Qom, Iran \\ 2 School of Science, Engineering and Environment, University of Salford, Manchester, UK \\ 3 Trauma Nursing Research Center, Kashan University of Medical Sciences, Kashan, Iran \\ ${ }^{4}$ Baharlo Hospital, Tehran University of Medical Sciences, Tehran, Iran \\ ${ }^{5}$ Bahman Hospital, Zanjan University of Medical Sciences, Zanjan, Iran \\ ${ }^{6}$ Researcher of Spiritual Health Research Center, Qom University of Medical Sciences, Qom, Iran \\ 7 Department of Nursing Education, Abhar School of Nursing, Zanjan University of Medical Sciences, Zanjan, Iran \\ 8 Department of Medical Education, Medical School, Tehran University of Medical Sciences, Tehran, Iran
}

\begin{abstract}
Introduction: The widespread use of advanced technology and invasive intervention creates many psychological problems for hospitalized patients; it is especially common in critical care units. Methods: This cross-sectional study was conducted on 310 patients hospitalized in critical care units, using a non-probability sampling method. Data were collected using depression, anxiety, and stress scale (DASS-21) one month after discharge from the hospital. Data analysis was performed using descriptive and inferential statistics. Results: 181 males and 129 females with a mean age (SD) of 55.11(1.62) years were enrolled in the study. The prevalence of depression, anxiety and stress were 46.5, 53.6 and $57.8 \%$ respectively, and the depression, anxiety and stress mean (SD) scores were 16.15(1.40), 18.57(1.46), 19.69(1.48), respectively. A statistically significant association was reported between depression, anxiety and stress with an increase in age, the number of children, occupation, education, length of hospital stay, use of mechanical ventilation, type of the critical care unit, and drug abuse. Conclusion: The prevalence of depression, anxiety and stress in patients discharged from critical care units was high. Therefore, crucial decisions should be made to reduce depression, anxiety and stress in patients discharged from critical care units by educational strategies, identifying vulnerable patients and their preparation before invasive diagnostic-treatment procedures.
\end{abstract}

Keywords: depression, anxiety, stress, critical care units; patient discharge

Received: 30 May 2020 / Accepted: 8 April 2021

\section{INTRODUCTION}

Rapidly expanding modern technology has provided medical personnel with the ability to run hospital wards, improve patient outcomes, enhance rehabilitative care, reduce complications and mortality $[1,2]$. Despite the successful physical treatment of patients, the use of technology and equipment in hospitals may pose a threat to patients' mental health [3]. Critical care units such as post-cardiac surgery intensive care units, cardiac care units and intensive care units could be an excellent example of these health-threatening environments [4]. Critically ill patients may be at particular risk of mental health sequelae, considering the advanced technologies, methods and procedures. Furthermore, the widespread use of advanced technology and invasive care contributes to creating a stressful environment for both hospitalized patients and critical healthcare staff $[5,6]$. These conditions have a more significant impact on the physical and mental health of patients [7].

In critical care units, environmental features such as space, noise, the complexity of medical equipment, twenty-four-hour lighting and disturbance of the circadian rhythm can contribute to patient stress [8-10]. Additional stress factors include invasive and noninvasive medical procedures such as clinical visits, urinary catheterization, central venous line insertion, tracheal suctioning, change of position, placement of nasogastric tubes, endotracheal intubation, unfamiliar 
equipment, and monitoring devices [11-12]. As a result, patients frequently exhibit a stressful reaction to care in critical care units [13].

It has been shown that stress factors among patients hospitalized in critical care units can provoke immediate and long-term emotional and psychological reactions [14]. Stress influences patients' moods as they may experience psychological symptoms such as hallucinations, delusions, sleep disorders, depression, stress, anxiety and psychosis [15]. Depression, anxiety, and stress are the most common of these disorders, leading to a reduced quality of life, emotional exhaustion, poor concentration and sleep disorders, as well as increased medical costs and prolonged hospitalization $[15,16]$.

It has been estimated that the prevalence of stress, depression, and anxiety is $60 \%, 30 \%$ and $40 \%$, respectively [17-19]. Consequently, these factors affect patients' health and lead to a delay in the recovery process. Moreover, discharge from the hospital may be prolonged as well as resulting in a reduced quality of life $[20,21]$.

These effects may not be limited to hospitalization and may continue for months after discharge with varying severity [20]. It has also been shown that the prevalence of mild depression after 3-6 months, 12 months, and two years of discharge ranged from $24 \%$ to $32 \%, 43 \%$ to $64 \%$ and $40 \%$ to $66 \%$, respectively [22]. Furthermore, it has been suggested that moderate-tosevere depression is reported in $17 \%$ of patients after two to 3three months of discharge from a hospital [23-25]. Also, admission to a critical care unit is associated with significant anxiety in patients and their family members [26], which is further exacerbated by an incomplete understanding of the patient's situation, allocation of a short time to explain intervention and inadequate patient preparation for invasive procedures by health care providers $[24,27,28]$.

Therefore, it is essential that nurses, doctors and other staff, recognize depression, anxiety and stress as consequences of stressors and provide an appropriate response to patients' mental health needs in critical care units [21]. Psychological factors can be significantly reduced by assessing vulnerable patients and support them [29].

As mentioned, it is essential to assess vulnerable patients. However, limited studies have been conducted in this area, and the findings are often contradictory. For example, ageing, the period of hospitalization, mechanical ventilation, education levels and patients 'painful memories are risk factors predisposing to the exacerbation of depression, anxiety and stress disorders $[30,31]$. A review of the literature indicates that few studies address which risk factors are the best predictors of mental disorders in critically ill patients.

According, this study aimed to assess the prevalence of depression, anxiety and stress among patients discharged from critical care units.

\section{- METHODS}

This cross-sectional study was conducted on patients discharged from a post-cardiac surgery intensive care unit, general intensive care unit (ICU) and cardiac care unit (CCU). Samples were chosen using a non-probability sampling method from Jul 5, 2015, to Mar 30 2016.

Inclusion criteria consisted of the physician discharge order, assessment of consciousness at hospital discharge, the ability to cooperate in completing the questionnaire, and hospitalization for more than 24 hours in a critical care unit.

Exclusion criteria included failure to contact access or access the patient by visiting, one month after discharge, low level of consciousness at discharge and reluctance to take part in the study.

Regarding the below equation a sample size of 287 patients was estimated given the $\mathrm{z}=1.96$ ( $\mathrm{z}$ statistic for the $95 \%$ level of confidence), $d=0.05$ (allowable error), and prevalence rate of psychological symptoms $25 \%$ in a previous study[8].

$$
n=\frac{z^{2} p(1-p)}{d^{2}}
$$

However, concerning the probability of samples' dropouts, the sample size was increased to be 340 patients.

This study was approved by the Ethics Committee of the Kashan University of Medical Sciences, Kashan, Iran.

All procedures performed in studies involving human participants were in accordance with the ethical standards of the institutional and national research committee and the 1964 Helsinki Declaration.

Written Informed consent was obtained from all patients or their guardians in the study.

The depression, anxiety, stress scale (DASS-21) was used for data collection, which is comprised of three 
self-reported scales that can measure the severity of depression, anxiety and stress [27, 32].

Each subscale consists of seven questions, randomly placed in a questionnaire, shown in Appendix 1.

There were twenty-one questions in total.

- Questions 18,14,12,11,8,6,1 related to Stress

- Questions 21,17,16,13,10,5,3 related to

- Questions 20,19,15,9,7,4,2 related to

The score for each question ranged from zero ("did not apply to me at all") to three ("applied to me very much, or most of the time"). The summation of questions' scores calculated the final score.

The scores related to the severity of symptoms were shown in Table 1.

After describing the research and obtaining written informed consent, demographic characteristics items were filled out by interviewing the patients or reading their medical records during admission and before discharge. Risk factors such as age, gender, number of children, education level, occupation, cause of hospitalization, hospital length of stay (LOS), type of medical units, mechanical ventilation, traumatic patients, and history of drug abuse were considered as important demographic characteristics that influence mental health after discharge. The DASS-21 questionnaire was completed one month after discharge. If the patients did not return to the hospital one month after the dis-

Table 1. The score of each subscale.

\begin{tabular}{lccc} 
Severity & Depression & Stress & Anxiety \\
Normal & $0-9$ & $0-14$ & $0-7$ \\
Mild & $10-13$ & $15-18$ & $8-9$ \\
Moderate & $14-20$ & $19-25$ & $10-14$ \\
Severe & $21-27$ & $26-33$ & $15-19$ \\
Highly severe & Up to 28 & Up to 33 & Up to 20 \\
\hline
\end{tabular}

charge to complete outpatient treatment, the researchers visited them in their homes after phone coordination and asked them to complete the questionnaire.

SPSS v. 20 was employed for data analysis. Normalization of the data was assessed using the KolmogorovSmirnov test. The t-test and chi-square were used to assess the difference between demographic variables and anxiety, depression, and stress. Analysis of variance for some variables related to anxiety, depression, and stress such as hospital LOS and occupation was conducted. Moreover, a multivariate analysis of linear regression was run to define independent predictors of anxiety, depression, and stress.

The level of significance was set at $\alpha=0.05$.

\section{RESULTS}

Of the original patients, 30 individuals were excluded from the research process due to death, re-admission, or unwillingness to continue the study.

This left 310 patients who participated in the study.

Of these 310 patients, 241 (77.7\%) were diagnosed as having cardiovascular problems, pulmonary oedema, hypertension, embolism, 20 (6.45\%) were diagnosed as having experienced trauma, 49 (15.85\%) were diagnosed as having internal medicine problems.

A flow diagram of participants through the study is shown in Figure 1.

The final cohort consisted of 181 males (58.4\%) and 129 females $(41.6 \%)$ with the mean age (SD) of 55.11(1.62) years (Table 2).

The prevalence of depression, anxiety and stress was $46.5 \%, 53.6 \%$, and $57.8 \%$, respectively, with stress being the most prevalent (Table 3 ). The mean (SD) scores for depression, anxiety and stress were 16.15(1.40), 18.57(1.46), 19.69(1.48), respectively.

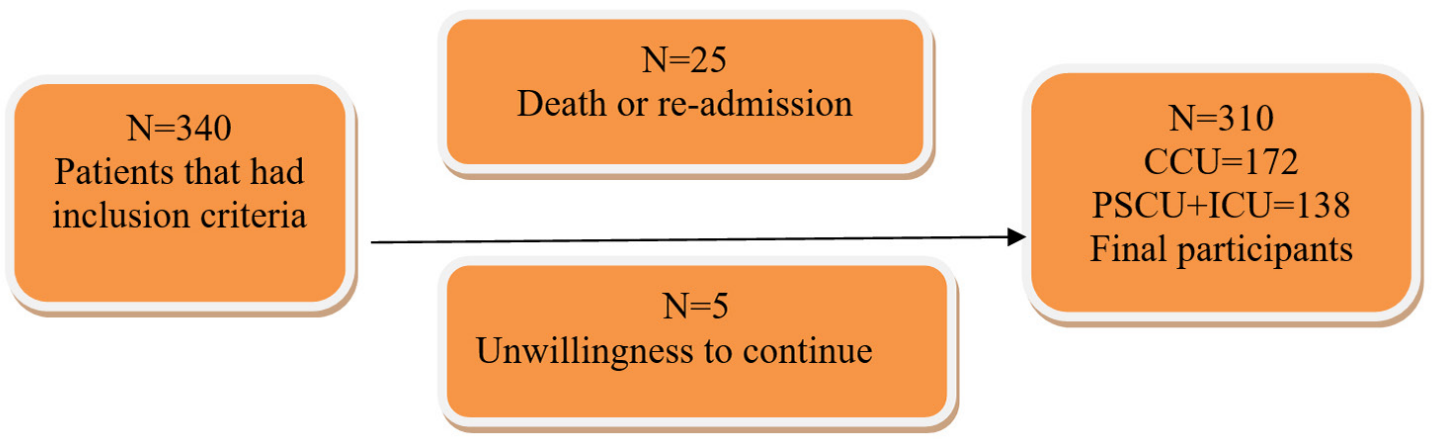

Fig. 1. A flow diagram of participants through the study. 


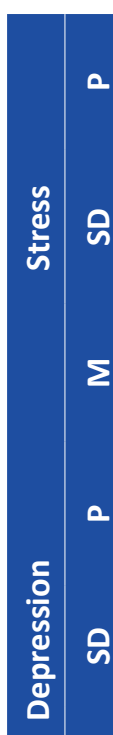

$\Sigma$ \& $: 0$ in

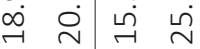

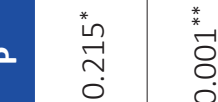

올

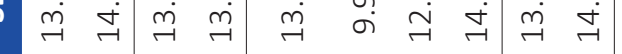

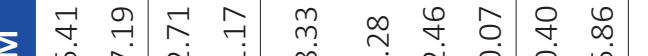

a

:

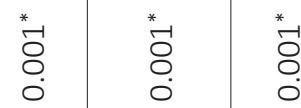

离

$\Sigma$

范

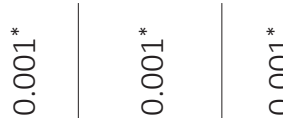

สี
岁

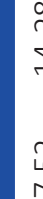

ஸे 更

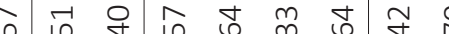
mif

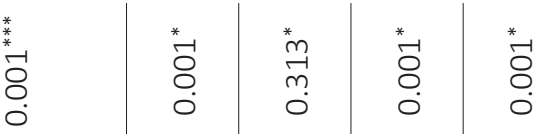

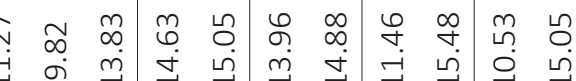

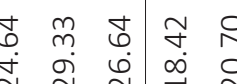

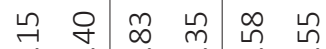

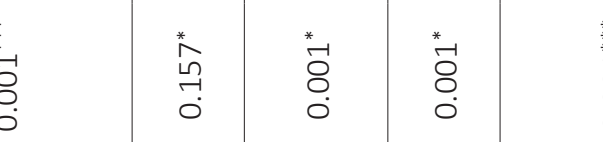

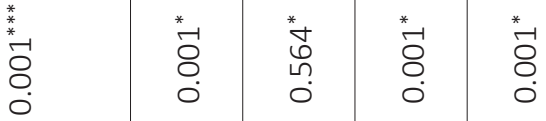
ఫิ สี

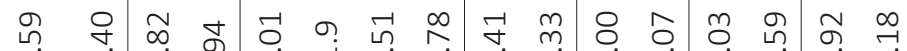
l

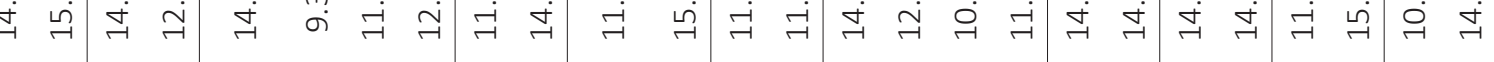
กี

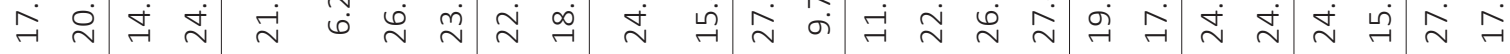

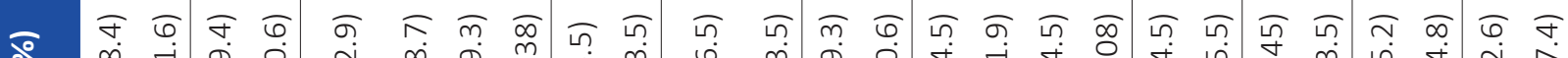

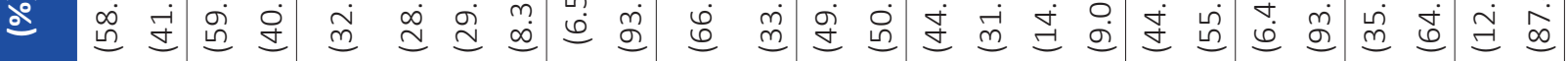

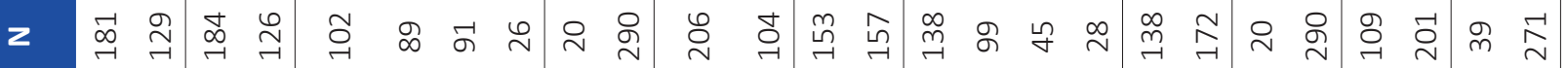
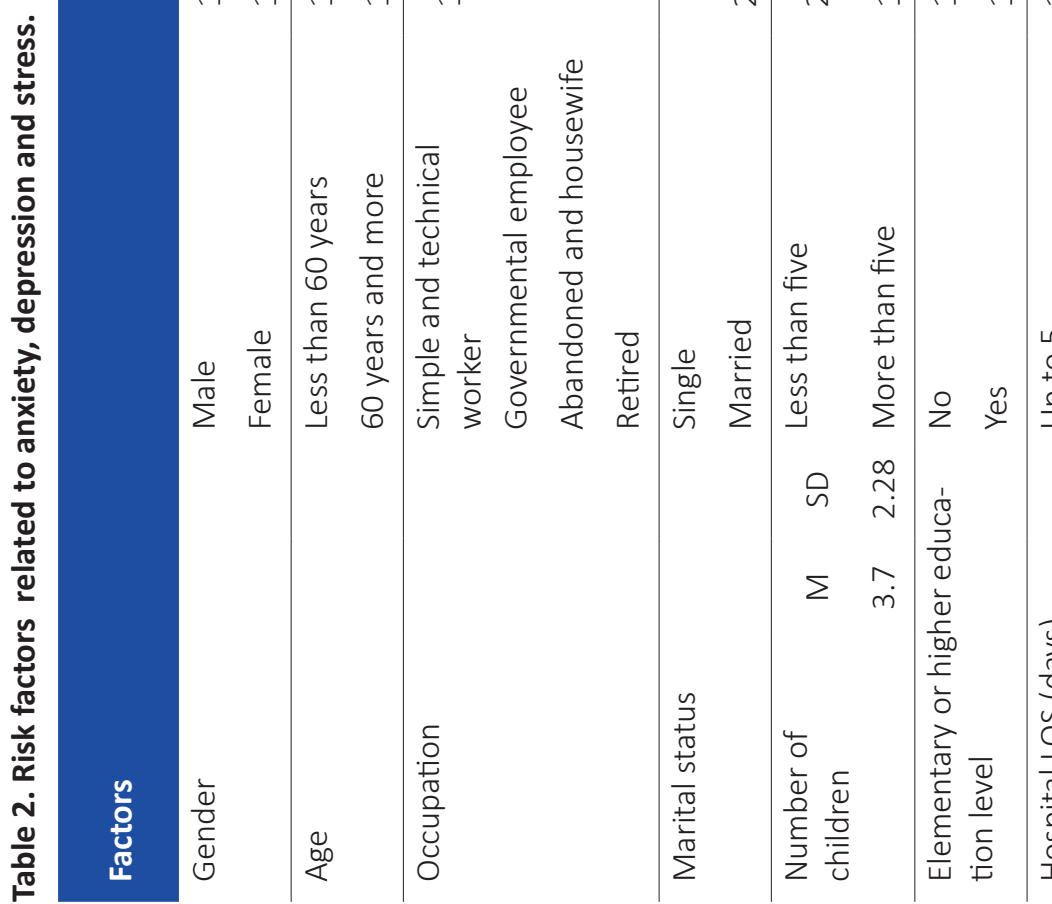

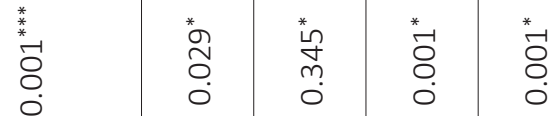
$\sum$ ए

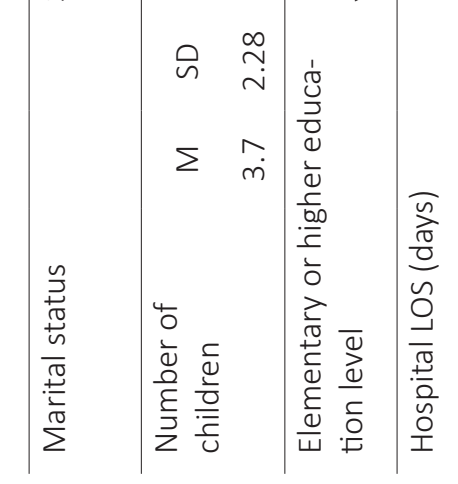

$\stackrel{\sim}{\sim}$

宽

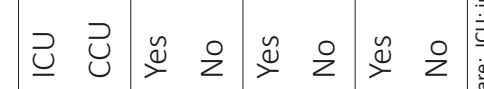

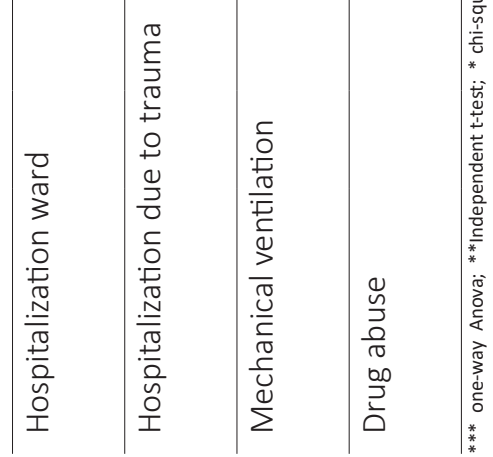


Table 3. The prevalence and mean (SD) severity scores for depression, anxiety, and stress.

\begin{tabular}{|c|c|c|c|c|}
\hline Mental symptoms & & Severity & $\mathbf{N}(\%)$ & $M(S D)$ \\
\hline \multicolumn{5}{|l|}{ Depression } \\
\hline & & Normal & $166(53.5)$ & $2.18(2.27)$ \\
\hline \multirow[t]{2}{*}{$N(\%)$} & $144(46.5 \%)$ & Mild & $10(3.2)$ & $8.10(0.31)$ \\
\hline & & Moderate & $53(17.1)$ & $11.92(1.43)$ \\
\hline \multirow[t]{2}{*}{$\mathrm{M}(\mathrm{SD})$} & $16.15(1.40)$ & Severe & $66(21.3)$ & $16.96(1.32)$ \\
\hline & & Very severe & $15(4.9)$ & $20.53(0.51)$ \\
\hline \multicolumn{5}{|l|}{ Anxiety } \\
\hline & & Normal & $144(46.4)$ & $2.13(2.52)$ \\
\hline \multirow[t]{2}{*}{$N(\%)$} & $166(53.6 \%)$ & Mild & $13(4.2)$ & $8.23(0.43)$ \\
\hline & & Moderate & $47(15.2)$ & $12.40(1.31)$ \\
\hline \multirow[t]{2}{*}{$M(S D)$} & $18.57(1.46)$ & Severe & $89(28.7)$ & $17.25(1.15)$ \\
\hline & & Very severe & $17(5.5)$ & $20.29(0.58)$ \\
\hline \multicolumn{5}{|l|}{ Stress } \\
\hline & & Normal & $131(42.2)$ & 2.00 (2.30) \\
\hline \multirow[t]{2}{*}{$N(\%)$} & $179(57.8 \%)$ & Mild & $16(5.2)$ & $8.50(0.51)$ \\
\hline & & Moderate & $38(12.3)$ & $11.68(1.27)$ \\
\hline \multirow[t]{2}{*}{$M(S D)$} & $19.69(1.48)$ & Severe & 95 (30.6) & $16.85(1.45)$ \\
\hline & & Very severe & $30(9.7)$ & $20.30(0.53)$ \\
\hline
\end{tabular}

The prevalence and the mean (SD) scores of "mild", "moderate", "severe" and "very severe" disorders, according to the DASS-21 scale are reported in Table 3. The most prevalent type being "severe" and "moderate".

Depression was significantly different from age, occupation, the number of children, elementary or higher education, hospital LOS, type of the critical care unit, mechanical ventilation, and history of drug abuse (Table 2). However, no statistically significant difference was observed between patients' gender, marital status, and hospitalization due to trauma with depression.

Anxiety and Stress were significantly different by age, occupation, marital status, number of children, elementary or higher education, hospital LOS, type of the critical care unit, mechanical ventilation, and history of drug abuse (Table 2). However, no significant difference was observed between patients' gender and hospitalization due to trauma with anxiety and stress. As a result, psychological symptoms such as depression, anxiety, and stress commonly related with ageing, occupation, increasing hospital LOS, number of children, education, type of the critical care unit, drug abuse, and mechanically ventilation.

According to the severity scores for depression, anxiety, and stress, severe had the highest prevalence with $21.3 \%, 28.7 \%$ and $30.6 \%$, respectively.

Table 4. Association between demographic and clinical characteristics with anxiety, depression and stress based on multivariate analysis.

\begin{tabular}{lccccccccc} 
Predictors & \multicolumn{3}{c}{ Anxiety } & \multicolumn{3}{c}{ Depression } & \multicolumn{2}{c}{ Stress } \\
Gender & S.E. & $\boldsymbol{\beta}$ & $\mathbf{P}$ & S.E. & $\boldsymbol{\beta}$ & $\mathbf{P}$ & S.E. & $\boldsymbol{\beta}$ & $\mathbf{P}$ \\
Age & .046 & .035 & .434 & .054 & .009 & .866 & .052 & .028 & .581 \\
Occupation & .049 & .076 & .111 & .058 & .006 & .914 & .055 & .050 & .353 \\
Number of children & .023 & .005 & .917 & .027 & .124 & .020 & .026 & -.033 & .508 \\
Marital status & .051 & .117 & .015 & .060 & .046 & .427 & .057 & .106 & .053 \\
Elementary or higher education level & .051 & -.374 & .000 & .060 & -.429 & .000 & .057 & -.333 & .000 \\
Hospital LOS (days) & .025 & .167 & .001 & .030 & .000 & .999 & .029 & .135 & .016 \\
Type of unit & .053 & .118 & .025 & .062 & .108 & .086 & .060 & .188 & .002 \\
Hospitalization due to trauma & .100 & .067 & .097 & .119 & -.037 & .446 & .113 & .011 & .805 \\
Mechanical ventilation & .055 & -.272 & .000 & .066 & -.097 & .125 & .063 & -.240 & .000 \\
Drug abuse & .066 & -.191 & .000 & .078 & -.210 & .000 & .075 & -.188 & .000 \\
\hline
\end{tabular}


Tables 4 illustrate other predictor factors associated with anxiety, depression and stress based on multivariate analysis.

According to the multivariate analysis, higher education level and drug abuse were the most common predictor factors for anxiety, depression and stress (Table 4).

\section{DIsCUSSION}

The primary purpose of this study was to assess the prevalence of depression, anxiety, and stress among patients discharged from critical care units after one month.

According to the DASS-21 scale, the severity of depression, anxiety and stress disorders, the most prevalent type were "severe" and "moderate".

Hatch et al. (2018) reported that the prevalence of depression, anxiety, and PTSD after three months was $45.7 \%, 41.0 \%$, and $22.0 \%$, respectively in an intensive care unit, which is not consistent with our study [33] due possibly to the use of different questionnaires and surveys in different months. Wiseman et al. (2015) reported that the prevalence of depression, anxiety and stress was $36.8 \%, 58.7 \%$ and $54.3 \%$ respectively. According to the DASS-21 scale, the most prevalent was moderate to "severe" of the disorder, which is consistent with the present study [34]. It can be concluded that over half of the patients may be depressed, anxious and stressed after discharge. The central point is, however, that the prevalence of different severity types of the disorders does not occur equally in patients and the patients are affected more by "severe". According to these findings, it could be concluded that the health care providers should take special care of "severe" of the disorder by taking effective care and psychotherapy to reduce the severity of these disorders. Also, they can comfort patients by providing practical information [21, 29]. Lerwick et al. (2016) have shown that providing information on the treatment process causes anxiety and stress for patients, though appropriate emotional communication with patients and descriptive treatment programs relieve symptoms [35]. However, there is a need for an appropriate critical care program in providing information and care [36].

In the present study, the most significant prevalence was related to stress, which was in agreement with both the Bienvenu (2018) and Wiseman (2015) studies $[18,34]$. It can be concluded that the high prevalence of stress can be related to its recognized immediate effect because stressors in the critical care unit instantly stimulate the patients. However, other disorders, such as anxiety and depression, develop over time. On the other hand, stress can be considered as the basis for other mental disorders $[15,16]$. Thus, by preventing stress, which is a sudden process, its complication such as anxiety and depression, can also be reduced. For this purpose, health care team members such as doctors, nurses and others in a critical care unit, could support patients in dealing with stressful situations by controlling the environmental conditions of the critical care unit, for example, light setting, voice control, improved sleep program, informing patients about invasive procedures and describing the usefulness of medical equipment such as ventilators and cardiac monitor [21, 29, 37].

The present study showed that psychological symptoms such as depression, anxiety, and stress had a significant correlation with age, occupation, increased hospital LOS, number of children, education level, type of the critical care unit, drug abuse, and mechanical ventilation. Hospitalization in critical care units leads to psychological and emotional reactions in patients [38]. Also, Paparrigopoulos et al. (2014) supported the idea that those who were hospitalized in these units for a prolonged length of stay have a higher risk of psychological issues [39]. According to the study of van der Schaaf et al. (2009) psychological disorders in patients hospitalized in critical care units and undergoing mechanical ventilation remain an important topic, even if social behaviours and gestures are improved after one year [40]. Płaszewska and Gazda (2012) reported that females declared stronger stress and depression than males [41], but in the present study, there was no significant gender difference. Previous studies did not report the effect of demographic risk factors, but the present study used linear regression analysis, which can control demographic risk factors and assess the intensity of these factors for depression, anxiety, and stress. Overall, attention to some patients' risk factors such as old age, single, low educated, ICU admission, prolonged hospitalization, mechanically ventilated and addiction, assist in identifying vulnerable patients and facilitates care programs.

Failure to assess and to monitor patients' mental disorder at the hospital admittance is another limitation. Taking into account the complexity of long-term tools to assess patients' mental status, and that the comple- 
tion of these questionnaires was beyond our patient's tolerance.

The DASS-21, used in this study, is the short-form version of DASS-42 in which the final score of each subscale is doubled. Sahebi (2005) assessed the criterion validity of the DASS in Iran with a population of 1070 people and a correlation between the depression subscale. The the Beck Depression Inventory scale was calculated at +0.70 , between the anxiety subscale and Zung Anxiety Inventory at +0.67 , and at +0.49 between the Stress subscale and Perceived Stress Inventory All correlations were significant [42]. According to Moradipanah (2015), the internal consistency of depression, anxiety and stress through Cronbach's alpha was reported as $0.94,0.92$, and 0.89 , respectively [43].

Due to a large number of in-hospital depression, anxiety and stress-related factors in discharged patients, evaluating all of these variables was challenging. For example, a review of the literature before carrying out this study suggested that variables such as delirium, sedation, and functional ability have not been investigated. Moreover, patient and family-related factors as discharge destination, return to work, return to independence, family support were not assessed due to lack of time and money.

Critical care staff should be aware of the potential for the patient to develop mental disorders after discharge from critical care units. These problems are mainly caused by preventable stress factors such a lack of adequate information on the treatment and diagnosis, use of sophisticated equipment, burden of monitoring devices, changes in patients' appearance, invasive interventions, lack of effective communication between the family and physician, wrong perception of the treatment process, and changes in the role of family members $[44,45]$. Staff working in critical care units can significantly reduce psychological factors through the use of various caring programs such as identifying vulnerable patients, education, consultation, physical and psychological support after discharge, and support networks [29].

\section{CONCLUSION}

The prevalence of depression, anxiety, and stress in patients discharged from critical care units were high, the most common type being "severe "according to the DASS-21 scale.
Also, some individual features and environmental factors in critical units such as ageing, unemployment, increasing hospital LOS, low-level education, increasing number of children, ICU, drug abusers, and mechanical ventilation were hazardous. Identification of risk factors associated with depression, anxiety, and stress and controlling them by critical care unit staff can lead to preventing mental disorders.

Thus, it is recommended that crucial decisions should be made to identify vulnerable patients and design educational strategies in admissions and after discharge from a critical care unit.

\section{ACKNOWLEDGMENTS}

This paper is part of an approved research project (ID: 9365), conducted with IR.KAUMS.NUHEPM. REC.1.779122 code of ethics at Kashan University of Medical Sciences. Hereby, we thank the Beheshti hospital of Kashan University of Medical Sciences for funding and supporting the study. The authors would like to thank Kashan University of Medical Sciences, Kashan, Iran. Moreover, all the patients who accompanied us in conducting the study are thanked. Also, we thank Hojjat Torkmandi for the best commenting the project.

\section{CONFLICT OF INTEREST}

We wish to confirm that there are no known conflicts of interest associated with this publication and there has been no significant financial support for this work that could have influenced its outcome.

\section{- FUNDING}

This study was funded by Kashan University of Medical Sciences (grant funding reference number: 9365), but this funding was not significant.

\section{DEFERENCES}

1. Maresova P, Klimova B, Krejcar O, Kuca K. Legislative aspects of the development of medical devices. Ceska a Slovenska farmacie : casopis Ceske farmaceuticke spolecnosti a Slovenske farmaceuticke spolecnosti. 2015;64(4):133-8. PMID:26459127

2. Sadaka F, Palagiri A, Trottier S, et al. Telemedicine intervention improves ICU outcomes. Critical care research and practice;2013:e456389. PMID:23365729. PMCID:PMC3556431. DOI:10.1155/2013/456389

3. Smith EC, Holmes L, Burkle FM. Exploring the Physical and 
120 The Journal of Critical Care Medicine 2021;7(2)

Mental Health Challenges Associated with Emergency Service Call-Taking and Dispatching: A Review of the Literature. 2019:16. PubMed ID:31637995

4. Amin P, Fox-Robichaud A, Divatia JV, et al. The Intensive care unit specialist: Report from the Task Force of World Federation of Societies of Intensive and Critical Care Medicine. J Crit Care. 2016;35:223-8. PMID:27444985,DOI: 10.1016/j. jcrc.2016.06.001

5. Dias DdS, Resende MV, Diniz GdCLM. Patient stress in intensive care: a comparison between a coronary care unit and a general postoperative unit. Revista Brasileira de terapia intensiva. 2015;27(1):18-25. PMID: 27444985(6), DOI: 10.1016/j. jcrc.2016.06.001

6. Lary A, Borimnejad L, Mardani-Hamooleh M. The Impact of a Stress Management Program on the Stress Response of Nurses in Neonatal Intensive Care Units: A Quasi-Experimental Study. J Perinat Neonatal Nurs. 2019;33(2):189-95. PMID:31021944. DOI:10.1097/JPN.0000000000000396

7. Van Mol MM, Kompanje EJ, Benoit DD, Bakker J, Nijkamp MD. The prevalence of compassion fatigue and burnout among healthcare professionals in intensive care units: a systematic review. PloS one. 2015;10(8):e0136955. PMID:26322644. DOI:10.1371/journal.pone.0136955

8. Scholten AC, Haagsma JA, Cnossen MC, Olff M, van Beeck $E F$, Polinder S. Prevalence of and Risk Factors for Anxiety and Depressive Disorders after Traumatic Brain Injury: A Systematic Review. J Neurotrauma. 2016;33(22):1969-94. PMID: 26729611. DOI:10.1089/neu.2015.4252

9. Puntillo K A, Max A, Timsit J, et al. Determinants of Procedural Pain Intensity in the Intensive Care Unit. The Europain Study. American Journal of Respiratory and Critical Care Medicine.2014;18(1):39-47. PubMed: 24262016

10. Righy C, Rosa RG. Prevalence of post-traumatic stress disorder symptoms in adult critical care survivors: a systematic review and meta-analysis. 2019;23(1):213. PMID:31186070. PMCID:PMC6560853.DOI:10.1186/s13054-019-2489-3

11. Netzer G, Sullivan DR. Recognizing, naming, and measuring a family intensive care unit syndrome. Annals of the American Thoracic Society. 2014;11(3):435-41. DOI:10.1513/ AnnalsATS.201309-3080T. PMCID: PMC4028736. PMID: 24673699

12. Dougherty L, Lister S. The Royal Marsden Manual of Clinical Nursing Procedures, 9th Edition, Professional Edition: John Wiley \& Sons; 2015. ISBN: 978-1-118-74592-2

13. Barth AA, Weigel BD, Dummer CD, Machado KC, Tisott TM. Stressors in the relatives of patients admitted to an intensive care unit. Revista Brasileira de terapia intensiva. 2016;28(3):323-9. DOI: 10.5935/0103-507X.20160055.PMCID: PMC5051192. PMID: 27737424

14. Moss M, Good VS, Gozal D, Kleinpell R, Sessler CN. An official critical care societies collaborative statement: burnout syndrome in critical care health care professionals: a call for action. American Journal of Critical Care. 2016;25(4):368-76. PMID:27309157. DOI:10.1097/CCM.0000000000001885
Available online at: www.jccm.ro

15. Barr J, Fraser GL, Puntillo K, et al. Clinical practice guidelines for the management of pain, agitation, and delirium in adult patients in the intensive care unit. Crit Care Med. 2013;41(1):263-306. PMID: 23269131.DOI:10.1097/CCM.0b013e3182783b72

16. Krag M, Perner A, Wetterslev J, Wise MP, Møller MH. Stress ulcer prophylaxis versus placebo or no prophylaxis in critically ill patients. Intensive care medicine. 2014;40(1):11-22. PMID: 24141808. DOI:10.1007/s00134-013-3125-3

17. Fulton JJ, Calhoun PS, Wagner HR, et al. The prevalence of posttraumatic stress disorder in Operation Enduring Freedom/ Operation Iraqi Freedom (OEF/OIF) veterans: A meta-analysis. Journal of anxiety disorders. 2015;31:98-107. PMID:25768399. DOI:10.1016/j.janxdis.2015.02.003

18. Bienvenu OJ, Colantuoni E, Mendez-Tellez PA, et al. Cooccurrence of and remission from general anxiety, depression, and posttraumatic stress disorder symptoms after acute lung injury: a 2-year longitudinal study. Critical care medicine. 2015;43(3):642. DOI: 10.1097/CCM.0000000000000752. PMCID: PMC4336582. NIHMSID: NIHMS631571. PMID: 25513784

19. McKinley S, Aitken LM, Alison JA, et al. Sleep and other factors associated with mental health and psychological distress after intensive care for critical illness. Intensive care medicine. 2012;38(4):627-33. PMID:22318635. DOI:10.1007/s00134012-2477-4

20. Rojas-García A, Turner S, Pizzo E, Hudson E, Thomas J, Raine R. Impact and experiences of delayed discharge: A mixed-studies systematic review. Health Expect. 2018;21(1):41-56. PMID: 28898930. PMCID: PMC5750749. DOI:10.1111/hex.12619

21. Papathanassoglou ED. Psychological support and outcomes for ICU patients. Nursing in critical care. 2010;15(3):118-28. PMID: 20500650. DOI:10.1111/j.1478-5153.2009.00383.x

22. Bienvenu OJ, Colantuoni E, Mendez-Tellez PA, et al. Depressive symptoms and impaired physical function after acute lung injury: a 2-year longitudinal study. American journal of respiratory and critical care medicine. 2012;185(5):517-24. DOI: 10.1164/rccm.201103-05030C. PMCID: PMC3297105. PMID: 22161158

23. Oeyen SG, Vandijck DM, Benoit DD, Annemans L, Decruyenaere JM. Quality of life after intensive care: a systematic review of the literature. Crit Care Med. 2010;38(12):2386-400. PMID:20838335. DOI:10.1097/CCM.0b013e3181f3dec5

24. Hart T, Fann JR, Chervoneva I, et al. Prevalence, Risk Factors, and Correlates of Anxiety at 1 Year After Moderate to Severe Traumatic Brain Injury. Arch Phys Med Rehabil. 2016;97(5):7017. PMID: 26707456. DOI:10.1016/j.apmr.2015.08.436

25. Herridge MS, Chu LM, Matte A, et al. The RECOVER program: disability risk groups and 1-year outcome after seven or more days of mechanical ventilation. American journal of respiratory and critical care medicine. 2016;194(7):831-44. PMID:26974173. DOI:10.1164/rccm.201512-23430C

26. Needham DM, Davidson J, Cohen $\mathrm{H}$, et al. Improving longterm outcomes after discharge from an intensive care unit: report from a stakeholders' conference. Critical care 
Available online at: www.jccm.ro

medicine. 2012;40(2):502-9. PMID:21946660. DOI:10.1097/ CCM.0b013e318232da75

27. Sundararajan K, Martin M, Rajagopala S, Chapman MJ. Posttraumatic stress disorder in close Relatives of Intensive Care unit patients' Evaluation (PRICE) study. Australian Critical Care. 2014;27(4):183-7. PMID: 24813077. DOI:10.1016/j. aucc.2014.04.003

28. Rusinova K, Kukal J, Simek J, Cerny V. Limited family members/ staff communication in intensive care units in the Czech and Slovak Republics considerably increases anxiety in patients relatives-the DEPRESS study. BMC psychiatry. 2014;14(1):21. PMID: 24467834. PMCID:PMC3931312 DOI:10.1186/1471$244 \mathrm{X}-14-21$

29. Wade D, Als N, Bell V, et al. Providing psychological support to people in intensive care: development and feasibility study of a nurse-led intervention to prevent acute stress and long-term morbidity. BMJ Open. 2018;8(7):e021083-e. PMID: 30037868. DOI: 10.1136/bmjopen-2017-02108330.

30. Davidson JE, Powers K, Hedayat KM, et al. Clinical practise guidelines for support of the family in the patient-centred intensive care unit: American College of Critical Care Medicine Task Force 2004-2005. Critical care medicine. 2007;35(2):605-22. PMID:17205007. DOI:10.1097/01. CCM.0000254067.14607.EB

31. Jolley SE, Moss M, Needham DM, et al. Point prevalence study of mobilization practices for acute respiratory failure patients in the United States. Critical care medicine. 2017;45(2):205. PMID: 27661864PMCID:PMC5520580. DOI:10.1097/ CCM.0000000000002058

32. Sukantarat KT, Williamson RC, Brett SJ. Psychological assessment of ICU survivors: a comparison between the Hospital Anxiety and Depression Scale and the Depression, Anxiety and Stress Scale. Anaesthesia. 2007;62(3):239-43. PMID:17300300. DOI:10.1111/j.1365-2044.2006.04948.x

33. Hatch R, Young D, Barber V. et al. Anxiety, Depression and Post Traumatic Stress Disorder after critical illness: a UK-wide prospective cohort study. Crit Care.2018; 22, 310. doi:10.1186/ s13054-018-2223-6.

34. Wiseman TA, Curtis K, Lam M, Foster K. Incidence of depression, anxiety and stress following traumatic injury: a longitudinal study. Scandinavian Journal of Trauma, Resuscitation and Emergency Medicine. 2015; 23(1):29. PMID:25882818. PMCID:PMC4389309DOI:10.1186/s13049-015-0109-z

35. Lerwick JL. Minimizing pediatric healthcare-induced anxiety and trauma. World journal of clinical pediatrics. 2016;5(2):14350. PMID:27170924. PMCID:PMC4857227. DOI:10.5409/wjcp.
The Journal of Critical Care Medicine 2021;7(2) • 121

v5.i2.143

36. Marco L, Bermejillo I, Garayalde N, Sarrate I, Margall M, Asiain MC. Intensive care nurses' beliefs and attitudes towards the effect of open visiting on patients, family and nurses. Nursing in critical care. 2006;11(1):33-41. PMID:16471296

37. Sharma B G, Evs M, Ms K, B G. Psychological evaluation of patients in critical care/intensive care unit and patients admitted in wards. J Clin Diagn Res. 2014;8(12): WC01-WC3. doi: 10.7860/JCDR/2014/10293.5297. Epub 2014 Dec 5. PMID: 25654014; PMCID: PMC4316320.

38. El-Masri MM, Fox-Wasylyshyn SM. Nurses' roles with families: perceptions of ICU nurses. Intensive and Critical Care Nursing. 2007;23(1):43-50. PMID:16971125.DOI:10.1016/j. iccn.2006.07.003

39. Paparrigopoulos T, Melissaki A, Tzavellas E, Karaiskos D, Ilias I, Kokras N. Increased co-morbidity of depression and post-traumatic stress disorder symptoms and common risk factors in intensive care unit survivors: a two-year follow-up study. International journal of psychiatry in clinical practice. 2014;18(1):25-31. http://dx.doi.org/10.3109/13651501.2013. 855793

40. van der Schaaf M, Beelen A, Dongelmans DA, Vroom MB, Nollet F. Poor functional recovery after a critical illness: a longitudinal study. Journal of rehabilitation medicine. 2009;41(13):1041-8. PMID:19893999. DOI:10.2340/16501977-0443

41. Płaszewska Z L, Gazda D. Emotional reactions and needs of family members of ICU patients. Anaesthesiol Intensive Ther.2012; 44(3):145-9. PMID:23110291

42. Sahebi A, Asghari MJ, Salari RS. Validation of depression anxiety and stress scale (DASS-21) for an Iranian population. Iranian Psychologists. 2005;4(1):299-313. http://jip.azad.ac.ir/ article_512443_en.html

43. Moradipanah F, Mohammadi E, Mohammadil AZ. Effect of music on anxiety, stress, and depression levels in patients undergoing coronary angiography. East Mediterr Health J. 2009;15(3):63947. PMID:1973178044. Ullman AJ, Aitken LM, Rattray J, et al. Intensive care diaries to promote recovery for patients and families after critical illness: a Cochrane systematic review. International journal of nursing studies. 2015;52(7):1243-53. PMID: 25869586. DOI: $10.1016 /$ j.jinurstu.2015.03.020

45. Shafipour V, Moosazadeh M, Jannati Y, Shoushi F. The effect of education on the anxiety of a family with a patient in critical care unit: a systematic review and meta-analysis. Electronic physician. 2017;9(3):3918. DOI: 10.19082/3918. PMCID: PMC5407223. PMID: 28461865 


\section{APPENDIX 1}

\section{Depression, Anxiety, Stress Scale (DASS-21) questionnaire.}

1 I found it hard to wind down

2 I was aware of dryness of my mouth

3 I did not experience any positive feeling at all

4 I experienced breathing difficulty (e.g. excessively rapid breathing, breathlessness in the absence of physical exertion)

5 I found it difficult to work up the initiative to do things

6 I tended to over-react to situations

7 I experienced trembling (e.g. in the hands)

8 I felt that I was using a lot of nervous energy

9 I was worried about situations in which I might panic and make a fool of myself

10 I felt that I had nothing to look forward to

11 I found myself getting agitated

12 I found it difficult to relax

13 I felt down-hearted and blue

14 I was intolerant of anything that kept me from getting on with what I was doing

15 I felt I was close to panic

16 I was unable to become enthusiastic about anything

17 I felt I wasn't worth much as a person

18 I felt that I was rather touchy

19 I was aware of the action of my heart in the absence of physical exertion (e.g. sense of heart rate increase, heart missing a beat)

20 I felt scared without any good reason

21 I felt that life was meaningless

\begin{tabular}{|c|c|c|}
\hline 0 & 1 & 2 \\
\hline 0 & 1 & 2 \\
\hline 0 & 1 & 2 \\
\hline 0 & 1 & 2 \\
\hline 0 & 1 & 2 \\
\hline 0 & 1 & 2 \\
\hline 0 & 1 & 2 \\
\hline 0 & 1 & 2 \\
\hline 0 & 1 & 2 \\
\hline 0 & 1 & 2 \\
\hline 0 & 1 & 2 \\
\hline 0 & 1 & 2 \\
\hline 0 & 1 & 2 \\
\hline 0 & 1 & 2 \\
\hline 0 & 1 & 2 \\
\hline 0 & 1 & 2 \\
\hline 0 & 1 & 2 \\
\hline 0 & 1 & 2 \\
\hline 0 & 1 & 2 \\
\hline 0 & 1 & 2 \\
\hline 0 & 1 & 2 \\
\hline
\end{tabular}

